DOI: $10.17805 / \mathrm{ggz} .2017 .1 .5$

\title{
Особенности эмоциональных состояний у студентов с ограниченными возможностями здоровья
}

\author{
B. А. СЕМЕРИКов \\ МОСКОВСКИЙ ГОСУДАРСТВЕННЫЙ ПСИХОЛОГО-ПЕДАГОГИЧЕСКИЙ УНИВЕРСИТЕТ
}

В статье приводятся результаты эмпирического исследования различий в уровнях тревожности, удовлетворенности жизнью и субъективного счастья, а также приведены типы эмоциональной направленности у студентов. Сравниваются показатели студентов с ОВЗ и условно здоровых студентов. Также показаны взаимосвязи между этими параметрами. Ключевые слова: тревожность; удовлетворенность жизнью; субъективное счастье; эмоциональная направленность; студенты с ОВЗ; студенты условно здоровые

\section{Features of emotional states of students with disabilities}

\section{A. SEMERIKOV \\ MOSCOW STATE UNIVERSITY OF PSYCHOLOGY AND EDUCATION}

Abstract: This paper presents the results of an empirical research of the differences in the levels of anxiety, life satisfaction and subjective happiness, as well as shows the types of emotional orientation among students. We compare performance of students with HIA and relatively healthy students. Also shown is the relationship between these parameters. Keywords: anxiety; satisfaction with life; subjective happiness; emotional orientation; students with HIA; conditionally healthy students.

Проблема эмоций у студентов с инвалидностью не в полной мере освещена в современной психологической науке. О том, как образовательный процесс влияет на состояние студентов, что руководит личностью, пришедшей в высшее учебное заведение (ВУЗ), что она чувствует, и какие эмоции ею движут. А ведь знание таких нюансов, как эмоции и чувства, могло бы помочь преподавателям поддерживать у учащихся интерес к занятиям, дало бы возможность правильно структурировать образователь- ный процесс, подстраиваясь к каждому студенту, и облегчило бы межличностный контакт как между преподавателем и студентом, так и между самими студентами. Особое значение эта проблема имеет для студентов с ограниченными возможностями здоровья (ОВЗ).

В нашем эмпирическом исследовании приняли участие 68 человек. Это были студенты московских вузов в возрасте от 17 до 25 лет, из которых несколько имеют постоянное место работы. Испытуемые были разделены на 2 группы: условно здоровые (34 человека), средний возраст которых составляет 20,1 года, и студенты с ОВ3 (34 человека), средний возраст которых составляет 22,1 года.

Основной гипотезой нашего эмпирического исследования было предположение о том, что эмоциональная направленность у студентов с ОВЗ и студентов условно здоровых различна. Студенты с ОВЗ обладают более высокой степенью тревожности по сравнению с условно здоровыми студентами. Также мы предположили, что студенты с OB3 обладают более низким уровнем удовлетворенности жизнью и более низким уровнем субъективного счастья. 
Исследование проводилось с использованием следующего комплекса эмпирических методик: тест эмоциональной направленности Б. И. Аодонова; «Шкала субъективного счастья» С. Аюбомирски; «Шкала тревоги» Ч. А. Спилбергера; «Шкала удовлетворенности жизнью» Е. Аиннера. Аля обработки полученных данных использовались методы: описательная статистика, U-критерий Манна - Уитни, статистический критерий однородности $\chi 2$ Пирсона, критерий согласия $\chi 2$.

В результате проведенного эмпирического исследования было выявлено, что по типу эмоциональной направленности студенты условно здоровые и студенты с ОВ3 не имеют значимых различий. Среди типов эмоциональной направленности у студентов с ОВ3 и условно здоровых самой распространенной является гносио-праксическая эмоциональная направленность. Минимальное число респондентов у студентов условно здоровых наблюдается по коммуникативно-альтруистическому типу эмоциональной направленности, а у студентов с ОВ3 - по акизитивно-гедонистическому (Семериков, 2016).

Аалее в таблице представлены средние значения выраженности тревожности, удовлетворенности жизнью и субъективного счастья в двух группах респондентов. Показатели личностной и ситуативной тревожности у студентов с ОВ3 несколько выше, чем у условно здоровых, но эти различия не являются значимыми.

Таблища

СРЕАНЕЕ ЗНАЧЕНИЕ И ЗНАЧИМОСТЬ РАЗАИЧИЙ ПОКАЗАТЕАЕЙ ЭМОЦИОНААЬНЫХ СОСТОЯНИЙ У СТУАЕНТОВ С ОВЗ И УС ОВНО ЗАОРОВЫХ

\begin{tabular}{|l|c|c|c|c|}
\hline & Вся вььорка & $\begin{array}{c}\text { Условно } \\
\text { здоровые }\end{array}$ & $\begin{array}{c}\text { Студенть } \\
\text { с ОВ3 }\end{array}$ & $\begin{array}{c}\text { Значение } \\
\text { критерия }\end{array}$ \\
\hline Аичностная тревожность & $47,84 \pm 8,55$ & $46,56 \pm 8,68$ & $49,12 \pm 8,36$ & 0,179 \\
Ситуативная тревожность & $44,22 \pm 8,29$ & $43,21 \pm 7,51$ & $45,23 \pm 8,99$ & 0,418 \\
Субъективное счастье & $18,3 \pm 4,7$ & $18,91 \pm 4,63$ & $17,68 \pm 4,80$ & 0,285 \\
Удовлетворенность жизнью & $20,55 \pm 6,4$ & $22,4 \pm 5,99$ & $18,85 \pm 6,46$ & 0,035 \\
\hline
\end{tabular}

П р и м е ч а н и : : различия, выделенные жирным шрифтом достоверны при $\mathrm{p}<0,05$.

Также не было выявлено значимых различий в уровне субъективного счастья у обследуемых групп студентов. Студентам с ОВ3 присуще более низкое среднее значение данного параметра, но это лишь на уровне тенденции. Полученные данные можно объяснить возрастом и статусом респондентов. Это молодость, которой присуще оптимистический взгляд на жизнь, амбиции и надежда на будущее, отсутствие самостоятельных решений жизненных трудностей. Это студенческая среда со своими традициями, позитивными переживаниями общности, дружбы, поддержки. Все это позволяет студентам с OB3, несмотря на проблемы со здоровьем, ощущать себя счастливым и не испытывать тревоги.

Вместе с тем, значимые различия были выявлены по параметру удовлетворенность жизнью. У студентов с ОВ3 этот показатель значимо ниже, чем у условно здоровых студентов. В целом в выборке студентов с ОВ3 20,6\% имеют высокий уровень удовлетворенностью жизнью; средний уровень удовлетворенности жизнью выявлен у 44,1\% респондентов; низкий уровень удовлетворенности жизнью обнаружен у $35,3 \%$. 
В группе студентов с условно здоровых это распределение следующее: $26,5 \%$ студентов имеют высокий уровень удовлетворенностью жизнью, 55,9\% - средний уровень и $17,6 \%$ студентов низкий уровень. Практически треть студентов с ОВЗ не удовлетворены своей жизнью. И это вполне очевидно. Здоровье в данном случае выступает как системообразующий фактор удовлетворенности жизнью.

Аанный результат подтверждает также и то, что такие показатели как субъективное переживание счастья и удовлетворенность жизнью, хотя и тесно связаны между собой, но не являются идентичными. Этот вопрос остается до сих пор дискуссионным в науке. Оба показателя часто используются как рядоположенные. Считается, что показатель счастья измеряет в основном чувства, а удовлетворенность - когнитивную оценку событий (Аргайл, 2003).

В зарубежной психологии широкое признание получила концепция, разработанная Э. Аинером и его коллегами в русле исследований субъективного благополучия личности. Согласно этой концепции удовлетворенность жизнью рассматривается как когнитивный компонент субъективного благополучия, не смешивающийся с аффективными компонентами. Удовлетворенность определяется как глобальная оценка реальной жизни через призму субъективных стандартов «хорошей жизни», которые конструируются самостоятельно или усваиваются в готовом виде из социального окружения. Общий уровень удовлетворенности в каждый конкретный момент времени свидетельствует о степени расхождения между жизненной реальностью и личными стандартами «хорошей жизни» (Савченко, Головина, 2006).

Встает вопрос, высокие показатели удовлетворенности жизнью будут ли нести в себе развивающий потенциал, стимулировать личность к развитию? Может быть, такая ситуации неудовлетворенности как раз и будет тем ресурсом саморазвития для лиц с инвалидностью? Нам близка позиция А. А. Аебедевой, рассматривающая проблему инвалидности не с позиции средового подхода и выраженности с ним дефицитов, а с ресурсной позиции. Она считает, что ведущую роль в продвижении к реализованному качеству жизни лиц с ограниченными возможностями здоровья играют психологические ресурсы личности, а также жизненная позиция по отношению к собственной инвалидности. Главным фактором, определяющим качество жизни, являются не условия среды жизнедеятельности, а сама личность и ее позиция по отношению к жизни в ситуации инвалидности, ее способность к активации собственного ресурсного потенциала. Именно личность, принимающая «вызов инвалидности», отталкиваясь от ограничений возможности здоровья, делает их основополагающим ресурсом саморазвития (Иебедева, 2012).

\section{СПИСОК АИТЕРАТУРЫ}

Аргайл, М. (2003) Психология счастья. СПб. : Питер. 271 с.

Иебедева, А. А. (2012) Позитивная психология как альтернатива традиционному клиническому подходу к изучению качества жизни лиц с ограниченными возможностями здоровья // Современная зарубежная психология. № 2. С. 17-28.

Савченко, Т. Н., Головина, Г. М. (2006). Субъективное качество жизни: подходы, методы оценки, прикладные исследования. М. : Институт психологии РАН, 2006. 170 с.

Семериков, В. А. (2016) Особенности эмоциональной сферы студентов с ОВ3 // «Молодые ученые - образованию». Материалы XV городской научно-практической конференции. М. : МГППУ. С. 302-303. 
Семериков Владислав Алексеевич - магистр, кафедра психологии и педагогики дистанционного обучения Московского государственного психолого-педагогического университета. Aдрес: 127051, Россия, г. Москва, ул. Сретенка, д. 29. Тел.: +7 (495) 632-99-83. Эл. адрес: semerikovva@fdomgppu.ru

Semerikov Vladislav Alekseevich - master, department of psychology and pedagogy of distance education at Moscow State Psychological and Pedagogical University. Address: 127051, Russia, Moscow, ul. Sretenka, d. 29. Tel.: +7 (495) 632-99-83. E-mail: semerikovva@fdomgppu.ru

Аля циттирования:

Семериков В. А. Особенности эмоциональных состояний у студентов с ограниченными возможностями здоровья [Электронный ресурс] // Горизонты гуманитарного знания. 2017, № 1. URL: http://journals.mosgu.ru/ggz/article/view/445 (дата обращения: Ад.мм.гггг.). DOI: $10.17805 /$ ggz.2017.1.5 